\title{
Indicator Culture in Sport for Development and Peace: A Transnational Analysis of Governance Networks
}

Kathryn Henne

University of Waterloo/Australian National University

\begin{abstract}
This article offers a transnational analysis of sport for development and peace (SDP) governance, focusing specifically on the role of indicator culture. Building on earlier attempts to use actornetwork theory to study law and governance, it illuminates how a focus on indicator culture requires considering how actors, both human and nonhuman, inform SDP governance. It draws upon multi-sited ethnographic research conducted at the United Nations and in Oceania and considers how bureaucratic mechanisms, political and funding mandates, and postcolonial ideologies converge. Taken together, they point to emergent tensions within the broader embrace of indicator culture across domains of governance.
\end{abstract}

\section{Introduction}

Sport for development and peace (SDP) research offers important insights into the challenges of using sport and physical activity for aid and humanitarian projects. While SDP scholarship tends to focus on the delivery of programs, researchers are increasingly studying the governance of SDP. This growing emphasis marks a well-documented shift from a focus on the 'government of a unitary state to governance in and by networks' comprised of a range of actors, including state and nonstate entities. ${ }^{1}$ The networks contributing to contemporary governance, which is better understood as 'the management of the course of events in a social system,' emerge through interactions between public and private actors, enforcement and accountability tools, overseeing institutions, and the power dynamics underpinning them. ${ }^{2}$ Existing analyses of SDP highlight a number of concerns that can stem from these public-private relationships: corporate and competitive interests threading themselves into the objectives and implementation of SDP, challenges in cross-cultural communication and programming, and some platforms reflecting donor desires rather than those of participating groups. ${ }^{3}$ For example, funding for SDP projects, although often promoted as aid, can privilege sport-specific objectives over the needs of communities receiving support. ${ }^{4}$ In other cases, civil society actors prioritise developmentoriented outcomes, using sport activities to support them. ${ }^{5}$ Despite the strong empirical focus on SDP program delivery, there remains little grounded research on SDP governance, particularly at the meso level where actors often set agendas and allocate resources for programming. ${ }^{6}$

This article offers an analysis of SDP governance networks, attending to the interplay between micro- and meso-level dynamics and how the rise of indicator culture, a contemporary trend in governance, implicates them. Indicator culture refers to the growing reliance on measurement tools, particularly in the form of quantification, which aim to provide clear assessments of program outcomes and greater accountability. ${ }^{7}$ Measurement and evaluation of SDP are pressing issues for scholars and practitioners alike, especially in light of findings that forms of evidence from the Global South ${ }^{8}$ tend to be devalued. ${ }^{9}$ Existing research suggests that the acceptance of 'positivist scientific evidence' exacerbates this problem by limiting the 'ability to incorporate knowledges from grassroots practitioners.' ${ }^{10}$ The analysis presented here extends 
this observation by examining how SDP governance systems privilege quantitative metrics in ways that foreclose possibilities of greater grassroots inclusion.

This article documents how different governance actors - such as development practitioners, members of nongovernmental organisations (NGO), SDP advocates, and community leaders - interact in the development of a national scheme designed to support SDP programs in the Pacific. Drawing upon qualitative research conducted at the United Nations (UN) and in Australia and the Pacific, I analyse how actors contribute to indicator culture. The findings destabilize assumptions that human decision-makers and practitioners dictate SDP governance agendas, an observation that affirms recent claims by socio-legal scholars that indicators are important technologies of governance. ${ }^{11}$ As technologies, indicators are more than innovative tools designed to strengthen assessment against key measures; they have transformative power. They enable the generation of 'new, transformed material realities' through their ability to make distinctly different things measurable and commensurable. ${ }^{12}$ In other words, technologies of measurement and evaluation actively shape governance processes. Thus, the study of governance requires broadening our consideration of who and what has agency in these systems.

The paper builds on earlier attempts (and their limitations) to use actor-network theory (ANT) to study governance. ${ }^{13}$ ANT is an analytic guide originally developed by Science and Technology Studies (STS) scholars to explain scientific and technological innovation in a way that does not privilege human actors or distinguish social relations from material ones. ${ }^{14}$ It has become an umbrella term for what is arguably a range of approaches that share a common commitment to understanding agency as rooted in the making of associations. At its core, it conceives of the world as a set of interactive relationships. According to Bruno Latour, a prominent scholar who helped to develop ANT, the attributes of all actors emerge from-as opposed to contribute to-constitutive dynamics. ${ }^{15}$ They make up heterogeneous processes that have material and semiotic dimensions. ANT's focus yields four distinct implications: (1) all entities can contribute to networks, meaning that all objects and persons can be actants (that is, have agency); (2) actants are not the same, but are shaped by social and historical conditions; (3) networks and actants (be they objects, entities, or humans) emerge from relational performances, making all dynamics inherently uncertain; and (4) actors are not inherently equal, nor do they have equal capacity to navigate or move across networks. ${ }^{16}$ In short, ANT is the radical embrace of relationality among things.

Used across disciplines, ANT anchors analyses that surpass cases of technological advancement or scientific knowledge production, even though it has not featured prominently in studies of aid and development. ${ }^{17}$ Certain entities become influential through their repeated performances and interactions, not their position or capital within a social field, as theorists like Pierre Bourdieu suggest. ${ }^{18}$ According to John Law, 'There is no social order. Rather, there are endless attempts at ordering. ${ }^{19}$ Rejecting the notion of a bounded structure to societal relations, ANT offers a guide for tracing actor-networks that come into being, some of which dissipate while others are sustained through regular engagement. Accordingly, ANT has received praise for moving beyond traditional social scientific approaches that rely on dichotomies, such as structure/agency, nature/culture, material/semiotic, and even human/non-human; however, some formulations of ANT have been criticised for being 'insufficiently radical' and losing sight of 
other formations of power and inequality at work. ${ }^{20}$ In response, some scholars have defended ANT as being a fundamentally different approach to the study of power, while others have made productive adaptations that are attentive to the particularities that shape their research sites. ${ }^{21}$

Adopting ANT's analytic insights, my objective here is to elucidate the important, and sometimes overlooked, relationships between various actants (human or otherwise) that cultivate and perpetuate indicator culture. This paper does not provide a complete picture of SDP governance at international or regional levels. Rather, it offers a 'situated' account of observable aspects of transnational networks as they coalesce around a case of SDP agenda setting in the Pacific. By evoking the term 'situated,' I borrow from Donna Haraway, meaning that my focus is on 'partial, locatable accounts of the world,' which are 'explicitly embedded within the contexts of its own production. '22 I concentrate on how actors' interactions reveal sometimes competing values and meanings between indicator culture, politics, and perceived needs of Pacific Island communities (usually articulated not by the communities themselves, but by program managers, aid workers, and other development professionals). This approach enables me to provide the necessary level of depth of analysis to counter narrow depictions of governance as merely the implementation of formulaic rules or procedures.

The remainder of the article proceeds in four parts. The next section provides an overview of the rise of indicator culture in global governance and how indicators operate as technologies of measurement and evaluation. It then outlines the methods used to collect the data for this paper and how ANT guides the analysis, followed by an analysis of interactions that reveal how indicator culture becomes part of SDP governance networks in Australia and the Pacific. The paper concludes with a discussion of how the actor-networks analysed here undermine the inclusion of grassroots knowledges. Further, it reflects on how metric-driven approaches to globalised social problems often negate the postcolonial conditions undergirding them and how ANT might aid in navigating indicator culture.

\section{Indicator Culture and Global Governance Networks}

Desires for greater transparency and accountability in global governance have contributed to the institutionalisation of indicator culture across domains as wide ranging as international law, development, finance, and public health. ${ }^{23}$ Simply put, indicators are a means to convey measures of performance in an abridged and easily comparable way. Kevin Davis, Benedict Kingsbury, and Sally Engle Merry define an indicator as:

a named collection of rank-ordered data that purports to represent the past or projected performance of different units. The data are generated through a process that simplifies raw data about a complex social phenomenon. The data, in this simplified and processed form, are capable of being used to compare particular units of analysis (such as countries, institutions, or corporations), synchronically or over time, and to evaluate their performance by reference to one or more standards. ${ }^{24}$

In other words, indicators are technologies that convey assessments about outcomes of interventions, but they do not provide full depictions of lived social realities. They are also not uniformly the same: some measure social phenomena, while others represent aggregated data on governance practices and institutions. Indicators are deeply interpretative. ${ }^{25}$ They are refined 
through deliberative practices, which require significant debate and reconsideration among experts. According to Davis, indicators that survive 'this intellectual gauntlet will tend to be biased in favour of powerful actors, thus compromising the indicators' reliability. ${ }^{, 26}$ That is, despite maintaining a veneer of objectivity, validity, and reliability, indicators are conditioned in ways that often privilege actors in the Global North and fail to reflect the viewpoints of peoples in the Global South. ${ }^{27}$ Although indicators aim to support good governance, they-as actants in governance networks - can present 'oversimplifications of complex social phenomena,' which can, in turn, mask important issues of power that affect networks beyond decision-making processes. $^{28}$

Merry's ethnographic research illustrates that interventions in the Global South using indicators are most successful when combined with local knowledges that provide a more robust picture of lived experiences and perspectives on the ground. ${ }^{29}$ Her observation offers an important reminder that indicators are among a myriad of actors operating within governance networks and are certainly not the only technologies at work. It would be a misnomer to assume that indicators are powerful merely because international institutions introduce them. Rather, following ANT's guidelines, their engagement with other actors in networks enables them to have agency. For example, the circulation of indicators can influence how different actors - such as 'donors, investors, voters, tourists, consumers, immigrants, and others'-perceive countries and regions across a number of regulatory issues. ${ }^{30}$ Through their presentation of data, indicators render social conditions ahistorical and decontextualized, which can affect how different actors relate to social problems and the broader 'distribution of power and resources. 31

Consider, for instance, how international institutions, such as the UN, approach the implementation of rights related to SDP. The 1978 UNESCO International Charter on Physical Education and Sport describes sport and physical activity as a fundamental right for all, presenting the Right to Play - a supporting right in other UN human rights declarations (not the NGO of the same name) - as its grounding in international law. The UN Convention on the Rights of the Child, which came into force in 1990, reaffirms 'the right of the child to rest and leisure, to engage in play and recreational activities appropriate to the age of the child. ${ }^{32}$ The development of indicators to monitor the realisation of the Rights of the Child has made outcomes associated with these rights measurable. One of the fifteen indicators used to assess the Rights of the Child $^{33}$ addresses the Right to Play through a detailed manual over 200 pages long. The indicators are not simply variables; they are both descriptive and instructive in terms of how to assess the realisation of the right. The Right to Play indicator requires looking for sufficient and suitable play space for children, whether the design facilitates use by all children, and evidence of exercise-related health outcomes. Collecting data on these considerations is 'straightforward,' but can 'bear little resemblance to what play looks like for most children in developing countries. ${ }^{, 34}$ By prioritising markers of play that are common in the Global North, the indicator inevitably fails to capture aspects of social life in lower-income countries, which may be important to understanding barriers and enablers to children's play in different countries and regions. In doing so, the indicator's embedded assumptions can undermine the generation of contextually specific data and incentivise certain kinds of responses over others. The Right to Play indicator encourages investment in physical recreational spaces, which may or may not be the appropriate means of supporting children's ability to play, especially in parts of the world where children may work or lack access to other forms of critical infrastructure. 
The remaining sections explain how indicator culture comes to inform a site of SDP governance, even though the UN never implemented specific indicators for SDP before closing the UN Office for Sport for Development and Peace (UNOSDP) in 2017. In fact, many of actors studied here embraced measurements that aligned with other areas of development in part because they were sceptical of the international office and its partnerships with corporate sport actors (such as the International Olympic Committee [IOC]). The following sections unpack how the subscription to quantitative measures contributes to the conceptualisation, design, and implementation of SDP in the Pacific. The inclusion of these metrics-including the belief in their necessity — is agential and has a transformative effect on SDP agenda setting.

\section{Methods of Studying SDP Governance Networks}

This paper is part of a larger project that examines the globalisation of SDP. I use multi-sited ethnographic methods to study the emergence and maintenance of SDP networks, because they enable in-depth exploration of cross-jurisdictional developments through the close study of how entities and ideas coalesce in sites of governance. ${ }^{35}$ These methods (e.g., participant observation, interviewing, sustained interaction) are traditionally associated with the study of communitylevel dynamics but have been used successfully to make sense of transnational dynamics. ${ }^{36}$ This approach rejects the assumption that global governance is abstract or distant compared to local settings. It acknowledges that so-called 'global' spaces are often micro-level sites of interaction between influential actors, which can have ripple effects in other parts of the world. ${ }^{37}$

Multi-sited ethnography is compatible with ANT. Both characterise the dualism of global/local as misleading and require researchers to pay careful attention to the details of interactions between actors. ${ }^{38}$ They share a commitment to understanding the particularities of material-semiotic relations, with ANT emphasising that all entities are prospective actants, not simply humans. Further, associations among actors are central to the creation of networks and their heterogeneous characteristics, making it impossible to observe their reach in one site. ${ }^{39}$ ANT does have limitations, though: some scholars contend that it fails to provide methods for capturing cross-network relations, the effects of actants' perceptions on their engagement, or the influence of disruptions to networks. ${ }^{40}$ These recognised limitations, combined with the transnational nature of SDP, support the need to account for other insights from STS. Haraway's emphasis on situated knowledges is a useful reminder to consider issues sometimes overlooked by ANT's preoccupation with interaction between actors - namely the role of power shaping their contextual conditions. Her advice calls for examination of the ideologies and inequalities that inform the production of authoritative claims, which requires consideration of the interrelated roles that context and worldviews play. ${ }^{41}$ According to Haraway, close, situated accounts help to accurately capture the grounded circumstances that foster them. ${ }^{42}$ Following Haraway, my use of situated is to underscore that this research does make grand claims about SDP governance. The empirical focus on the interactions among actors still reflects traditional ANT tenets; however, it accounts for conditions specific to the sites of governance networks I observed-as well as the technologies, interests, and tacit knowledge that became part of the SDP initiatives they created and supported.

In accordance with ethics approvals, the research centred around formal governance networks that influence regional SDP programming, the funding for which disproportionality 
comes from higher-income countries. ${ }^{43}$ Qualitative research entailed observations of events that took place at the UN Headquarters in New York City, Australian organisations contributing to SDP governance, and conferences targeting SDP professionals working in Oceania and the Pacific between late 2012 and 2015; analysis of nearly 150 documents that capture regional SDP initiatives; and key informant interviews with actors involved in SDP governance. ${ }^{44}$ Recognising a potential imbalance in the perspectives revealed through observations and document analysis, I also interviewed Pacific peoples who engage these processes. In total, the data come from observations of SDP agenda-setting and planning meetings, professional conferences and trainings, and stakeholder outreach; textual analysis of international and regional SDP documents, evaluation reports, and policies; and formal interviews with 26 participants who are intermediaries in governance networks, a sample that includes SDP advocates and practitioners (9), development workers in the Pacific (6), Pacific representatives and community leaders (7), and sport diplomacy policymakers (4). ${ }^{45}$ The perspectives of interviewees reflect their distinct entry points into SDP governance networks and their different backgrounds, which include cultural and ethnic ties to Aotearoa/New Zealand, Australia, Cook Islands, Fiji, Samoa, and Tonga. Recruiting participants required both purposive and snowball sampling in which I relied heavily upon participants to introduce me to others in their network. Given that I sought to elicit in-depth information, interviews mostly entailed open-ended questions, with a focus on their understandings of and experiences with SDP governance, as well as targeted questions to clarify previous statements or actions I had observed.

Supplementing the data are insights gleaned from my collaborations with SDP programs serving Pacific peoples and consultations with experts who work in the areas of health equity, transnational migration, and community change in the Pacific. My working relationships and ongoing dialogues with colleagues of Pacific heritage about my research and engagement were important checks for me as a White, North America-born researcher. Despite my efforts to be reflexive, consideration of their feedback during data collection and analysis helped me to see limitations within my ability to fully grasp nuances of diverse Pacific norms and values. Analysis followed principles of crystallisation and immersion, which required reflecting on the various angles of experience presented by the different data, taking additional steps to ensure adequate immersion (through, for example, close readings of transcripts and revisiting audio recordings), and conceptual note taking. ${ }^{46}$ This enabled me to discern emergent themes and contradictions before I began open coding. Following the initial phase of coding, I conducted a fine-grained analysis to identify how the data reveal different connections, perceptions, and disjunctions between the actors involved. Guided by ANT, coding and analysis did not privilege human actors over others, instead focusing on moments of interaction. It was at this stage that it became clear that the influence of indicator culture was powerful and in ways not limited to evaluation. The fine-grained analysis enabled me to build systematic arguments about how actors, including technologies of governance, engaged each other, refining them in relation to my analytical notes as well as documented feedback from Pacific colleagues.

\section{Developing and Implementing SDP Initiatives for Pacific Island Nations}

How indicator culture becomes manifest in SDP is observable within the development of regional initiatives. SDP practitioners and policymakers contributing to the Australian government-funded Pacific Sports Partnerships Program (PSP) offer a case in point. Their responses reveal not only how they perceive indicator culture, but also how they anticipate and 
respond to shifts in governance networks as they design and tailor measures for programs being delivered in Pacific Island nations, such as Fiji, Samoa, Tonga, and Vanuatu, as well as Melanesian countries, such as Papua New Guinea. For context, the PSP scheme fits within the larger Australian government aid and diplomacy portfolio. In recent years, investment in sport diplomacy has remained relatively stable despite cuts to aid budgets. ${ }^{47}$ The Australian Department of Foreign Affairs and Trade (DFAT) frames sport as an effective means of 'helping developing countries achieve positive results' in efforts to reduce the risk of non-communicable diseases (NCDs), support social cohesion, equip women and girls with leadership skills, and teach children 'important life skills, including leadership, teamwork, respecting rules, discipline and perseverance. ${ }^{48}$ DFAT-supported programs target individuals as a way to promote broader social change. Prior to embracing the language of sport diplomacy, DFAT representatives considered and adopted other approaches, including 'sport for development,' sport outreach, and 'development through sport' (an attempt to reposition sport as supporting, not replacing, existing development projects). Developing each of these agendas required significant work by officials who tried to balance the demands of the aid and development portfolio with desires to promote sport-related programs. To illustrate how indicator culture implicated their decisions, the following paragraphs consider the development of a scheme that supported the use of sport to pursue health-related development goals in the Pacific.

\section{Using Metrics to Ensure Development through Sport}

A preoccupation with ensuring government-funded SDP programs constituted 'true development' (to use participants' language) was a primary concern during the development phases. This language reflected the apprehensions of the civil servants tasked with designing the SDP initiative, particularly around prospective funding cuts to the aid and development portfolio and a changing global SDP landscape. They anticipated that elite sport organisations, such as the IOC and Australian professional sports leagues, and international legal institutions, such as the $\mathrm{UN}$, would become increasingly influential in SDP governance. With government funding for aid and development on the decline, some felt the circumstances invited elite sport organisations to have greater influence. In interviews, officials acknowledged that sport organisations can provide large donations to support individual programs, but explained that such contributions are rarely sustainable because funding usually ends after the sponsor no longer sees value in local outreach to local communities — say, for instance, following the conclusion of a mega-event. ${ }^{49} \mathrm{~A}$ senior administrator cited the failure of development projects 'doing extraordinary work' in South Africa after the 2010 Fédération Internationale de Football Association (FIFA) World Cup, describing it as a warning of what could happen with more corporate entities involved in SDP. He was troubled by the prospect of the UNOSP partnering with the IOC or other professional sport administrators when setting international SDP agendas and supporting public health campaigns. ${ }^{50}$ Other officials disclosed what they saw as 'completing interests' between the priorities of SDP initiatives (e.g., social, educational, and health objectives) and those of national and global sports organisations (e.g., competitive and high-performance goals). ${ }^{51}$ They emphasised that SDP programs should clearly demonstrate their contributions to development, goals they thought corporate sport involvement would undermine.

According to aid and development coordinators, this foreboding environment meant they needed to create a government-backed initiative that had clear aims to only support SDP programs that could deliver development-oriented outcomes. They therefore tailored the scheme 
so that it appealed to indicators used in other areas of development. For them, the primary task was to ensure SDP programming was compatible with the UN Millennium Development Goals (MDGs), even though many were sceptical of the UNOSDP reports on the effectiveness of sport for development to date. ${ }^{52}$ They felt pressure to align the SDP initiative with one or more MDG target areas (e.g., disease prevention, economic empowerment) and to ensure there was evidence of positive progress. Some hoped that doing so would 'set the standard' for other SDP initiatives in ways that would instill a 'healthy scrutiny' of sport-related programs and their ability to deliver positive outcomes.

Making these decisions prompted debate among six key decision-makers, most of whom were men of Anglo-European descent. While some of them had worked in the Pacific, just as many of them had no experience in the region. Two men had sport management experience. Their differences of opinion reflected their professional backgrounds. Some believed strongly that sport participation in and of itself contributed to personal empowerment and thus better health, a point that some scholars argue is tacit knowledge that SDP agencies often assert as facts. ${ }^{53}$ Only the decision makers with backgrounds in sport, however, believed that stating such outcomes-like 'fortitude' or 'increased self-confidence'-justified a 'true' development program. Most were critical of the seemingly intangible benefits of sport participation, even denouncing some international agendas for promoting SDP without strong evidence.

Regardless of their position, the officials wanted to see if SDP could translate into 'real' - that is, quantitatively measurable - effects, particularly in relation to the MDGs. One openly sceptical official stated, 'We cannot sacrifice real development for elite training camps or corporate sport PR [public relations] campaigns.' He suggested that adapting more established indicators used in other development contexts to support SDP could help protect SDP from being dictated by corporate sport interests. Against this backdrop, his colleagues agreed. Indicator culture would thus come shape their discussions and decision-making processes, as well as their conceptions of what constituted a 'real' program outcome. Thus, in its initial stages, the development of the initiative oriented around the team's perceptions of the wider governance landscape, not the groups agreeing to or participating in programs delivered in Pacific Island countries. As conveyed by one person involved, 'We have to use it [SDP] to meet the MDGs. I don't buy what [a colleague] says, that just doing sport is an inherently good thing. We need real results and outcomes. Progress.' The strategy of first determining which goals could be effectively targeted through sport, he argued, supported a broader objective: to provide evidence of sport's specific value for development and peace endeavours. Other interviewees working on the initiative concurred that doing so would ensure the sustainability of SDP.

After some debate, the Australian team tasked with designing the scheme agreed that SDP could be used to counteract non-communicable diseases (NCDs), such as Type 2 diabetes, cancers, and cardiovascular diseases, which account for 89 percent of deaths in the Pacific. ${ }^{54}$ Not only was this issue of great importance to many stakeholders, but it also could be assessed using quantitative measures. Their subscription to quantitative reasoning would, in turn, shape the initiative. Officials emphasised the high rates of obesity in the Pacific, an identifiable risk factor for NCDs. Promoting physical activity through sport supported what they saw as a clear and tangible objective (weight reduction) that could facilitate measurable outcomes against the goal of reducing NCD risk. Data that showed women in Pacific Island countries become less 
physically active after secondary school (through adulthood as they take on more responsibilities within and beyond the household) bolstered their justification for gender-specific targets. Although this observation applies to many countries within and beyond the Pacific, Australian policymakers were quick to use it as grounds for justifying increased sport participation, contending that it would also support women's empowerment by disrupting patriarchal dynamics in the Pacific. Thus, they suggested, programs would also deliver on gender and development goals, which were longer-term objectives that could not be as easily quantified. Health metrics, however, could demonstrate impact in the shorter term.

In designing the scheme around the ability to generate evidence that satisfied MDG measures, decision-making processes often negated the diversity of conditions across the Pacific. When officials did consider these issues, they demonstrated a limited understanding of social relations in the areas in which they planned to deliver SDP programs. For example, consultation processes among Australian government officials often conflated 'physical activity' with recreation, failing to consider the nature, quantity, or significance of Pacific women's labour, domestic or otherwise, as well as the time constraints they may face because of their responsibilities. ${ }^{55}$ As a result, the SDP governance network being constructed rendered invisible the existing communal networks to which these women are important contributors. Rather than seek out information on the array of factors that Pacific women navigate, many coordinators consulted data sets and statistics on their high obesity rates. In doing so, the causal logic embedded in quantitative reasoning became grounded in the foundations of the scheme: sport was a good weight-loss method because it increased physical activity, which would reduce NCD risk. Notably, though, they overlooked public health evidence that suggests the high obesity and NCD rates in many Pacific Island countries are more closely linked to diet, particularly the consumption of low-quality meats that are high in saturated fat and imported from Australasia. ${ }^{56}$ The preoccupation with measuring outcomes did not equate to considering evidence more widely, even in relation to the initiative's health-oriented goals. Instead, metric-driven priorities translated into the scheme only accounting for-and, in turn, privileging-individual-level change (weight reduction) as documented in relation to an intervention (sport) implemented at the local level.

Their approach to lowering NCD risk meant SDP programs would be subject to clear accountability mechanisms in which measurement was narrow in scope. The scheme would encourage other actants (e.g., SDP program coordinators) to repeatedly interact with quantitative measures, sustaining the vitality of indicator culture within governance networks. Accordingly, the officials designing the scheme sought out expertise that could ensure the 'quality evaluation' of programs. In interviews, they explained that proposals using qualitative and participatory methods were 'rather light.' In contrast, one senior administrator welcomed the knowledge of colleagues who had experience in other areas of development, recognising their 'strong and really established reputation' and known skills - such as 'solid training in economics' - as desirable attributes. Instead of asking if their background prepared them to capture effects of sport-specific programs, he presented their expertise as the kind that could certify SDP programs' legitimacy, particularly to governance actors who assess the portfolio based on the presentation of clear outcomes. With the establishment of indicators as constitutive elements of the governance of aid and development, he believed the logical — in fact, necessary — move was to appeal to them. 


\section{Complications Revealed through Consultation and Practice}

Although government officials insisted that consultations with Pacific stakeholders were important, they settled on the core elements of program evaluation prior to doing so. When they did reach out, they mainly received advice from men. This male dominance stems in large part from societal dynamics: despite strong matriarchal traditions in some Pacific countries, women's positions of power are often limited to their familial roles, with few women holding political positions. ${ }^{57}$ Reflecting on early meetings, most Australian officials conveyed frustration around their counterparts' hesitation to 'buy into' an initiative that targeted women. Acknowledging that Pacific leaders expressed apprehensions about unsettling social and communal relations, the officials rendered their concerns as the patriarchal defence of 'traditional' norms. What they failed to consider, though, was how the design of the initiative also negated Pacific women's perspectives by not accounting for gendered circumstances that different women navigate. In the absence of wider consultation, the reliance on quantitative measures for program evaluation communicated at least two ideologies that do not resonate in Pacific Island communities. First, the measures valued weight loss, something Pacific leaders did not necessarily see as desirable or relevant to community health. Second, they reinscribed progress onto individual achievementan idea that is counterintuitive to Pacific people's relational sense of identity, which is deeply rooted in familial and communal networks.

Essentialist notions of gender hierarchies crept into the language of some Australian policymakers' justifications for SDP in the Pacific. Some assumed that sport would, to use the words of one participant, 'get the women out of the house and away from controlling families,' giving them a 'social outlet outside the Church... since the Church can sometimes be part of the problem.' Although women's disproportionate obligations within these institutions are often barriers to pursuing private-sector work, they are not as merely sources of oppression. Casting them in this way neglected the important ways that familial and church connections can provide women in the Pacific with forms of social protection in the absence of strong state-sponsored provisions. ${ }^{58}$ Accordingly, policymakers often dismissed the possibility that male Pacific leaders might have legitimate, albeit still gendered, concerns that SDP could negatively affect the social fabric of communities and create new tensions. Doing so disregarded the distinct contours of Pacific governance networks, which would inevitably affect SDP outcomes. In doing so, institutions such as the Church - themselves heterogenous in nature-emerged as homogenous forces for SDP policymakers to overcome (not unlike how officials characterised elite sport).

Interviewees involved in SDP program design and implementation, particularly those of Pacific Island heritage, offered a different perspective. They emphasised the importance of working with local actors in these institutions. Interestingly, in narrating their importance, some acknowledged that their corporate partners, including professional sport organisations, understood how these partnerships are essential to building relationships that support better outreach and engagement. The forms of accountability expected from these partners, too, varied from metrics-driven efforts. As explained by one program coordinator, who was affiliated with a professional sport that had a recognisable number athletes of Pacific Island heritage,

It's probably a bit more flexible for us in some ways. They [sport leaders] get the power of sport in people's lives... For us, it's about culture and keeping those values, about 
showing [Pacific] people that we share them and are giving back to communities where we can. So, we still get results.

Setting aside questions related to how these efforts supported corporate interests, he went onto to explain that his goal was to understand and share the benefits of SDP, which required more than 'numbers.'

Other program coordinators shared his sentiments and emphasised the importance of engaging participants in SDP programs as interlocutors. In fact, many of the SDP conferences, knowledge sharing activities, and trainings that I attended focused explicitly on the use of participatory approaches for eliciting feedback from program participants. Advocacy for improving these methods seemed to appear in stark contrast to metric-driven approaches; however, nearly all interviewees framed both approaches as necessary for more accurately capturing participants' perspectives and experiences. They saw the value in different kinds of evaluation, but acknowledged the growing importance of having quantitative evidence of program effectiveness. Some cautioned that the trend could lead to 'focusing on the wrong things' in terms of what SDP contributes to development. Their comments drew attention to the diversity of actors and perspectives in SDP. Though the government-funded initiative appealed to indicator culture, its requirements were only parts of larger actor-networks. They did not necessarily dictate the terms of SDP programs or prevent the inclusion of grassroots knowledges - although they did provide disincentives for doing so, especially when SDP program budgets were tight and coordinators needed to prioritise metrics to justify funding.

Conceiving of SDP governance relationships as networks highlights the opportunities for other actants to emerge and engage in influential ways. The program Kau Mai Tonga, Ke Tau Netipolo ("C'mon Tonga, Let's Play Netball") exemplifies the hybridity that can result in practice. Its mission addresses international objectives (e.g., health, gender empowerment) while incorporating community-oriented values and approaches. Grassroots engagement aided in identifying barriers to female sport participation, enabling the development of strategies to address concerns - and, in some cases, stigma - about adult, particularly married, women being involved in sport. ${ }^{59}$ Further, the program targets women, but it also recruits community advocates and develops media campaigns featuring respected leaders, such as doctors and church leaders, to communicate broader, constructive messages about women's sport participation. Kau Mai Tonga, Ke Tau Netipolo nonetheless still reflects the influence of indicator culture. It promotes individual weight management to counteract obesity. There are requirements to measure and record participants' body weights at annual tournaments, offering prizes to those who lose the most weight. ${ }^{60}$ Although embracing positive and community-oriented values through sport, the program endorses a weight-loss competition among participants. The scales used to collect data for comparing and assessing participants' weight are technologies that support and reinscribe metric-driven governance. Endorsing this form of self-tracking, as Kate Crawford and colleagues argue, does more than encourage self-awareness; it works in the reshaping subjectivity and perceptions of one's body and self. ${ }^{61}$ With governance frameworks providing no incentives for research on the socio-cultural implications of the program, the few evaluations available do not consider possible negative consequences of promoting individual weight management practices, such as issues related to body image or self-esteem, nor do they account for possible communal changes that may stem from widespread and long-term 
participation. ${ }^{62}$ When aid and development coordinators discussed how to document and track health-related outcomes based on weight loss, there was no mention of these potential effects.

In sum, indicator culture implicates SDP governance networks through repeated engagements that reiterate the use of positivistic tools for performance assessment. The apparent institutionalisation of quantitative forms of evaluation may reflect some governance actors' tacit embrace of metrics; however, attending to them as actants reveals that they are component parts because of active engagement. Development evaluation requires their repeated performance and interaction with measurement and assessment tools.

\section{Conclusion}

Like other critical analyses of the globalised dynamics that inform SDP, this article draws attention to how governance processes can contribute to unequal power relationships. Its focus on indicator culture, however, is distinct, as is its adaptation of ANT. ANT's material-semiotic sensibilities renders the influence of indicator culture as something more complex than a hegemonic move that disregards grassroots knowledges under the veneer of generating better evidence of impact. It aids in understanding how metrics are among the constitutive - and increasingly repeated - actants within governance. Although one could narrative this analysis as a story of different local (human) actors resisting, accepting, or negotiating global patterns, it would negate the agential ways that various kinds of actors interact with each other in the creation of SDP governance networks. Looking at these dynamics through a situated ANT lens makes clear how metrics come to interact with policymakers, funding imperatives, ideologies, (mis)understandings of difference, and strategies for neutralising other actors (such as elite sport organisations). As such, this analysis points to the underutilization of ANT as a method that can be used to excavate power in ways that may be linked to but not necessarily determined by geopolitics or biopolitics. In doing so, however, it also offers a reminder of ANT's possible limitations so that it does not privilege immediate connections between actors over the meaningful ways that context and power inform how they come together in the creation-and possible fracturing - of networks.

As this case study of SDP attests, ANT can illuminate how localised negotiations inform what indicator culture can make visible and what it can veil. Here, the inclusion of quantitative metrics reinscribes and buttresses the influence of Northern worldviews, supporting existing criticisms of indicator culture and governance institutions. They, as Anna Agathanelou and L.H.M. Ling argue with regard to international governance more generally, are laden with 'white, male, and bourgeois' values that are not always visible on the surface. ${ }^{63}$ The use of ANT shows how these values become embedded through interactions between actants, providing important insight into localised dynamics that come to appear global. Further, in this context, technologies of measurement and evaluation fail to account for many actor-networks that undermine Pacific peoples' health, such as the inability of some Pacific Island states to provide adequate social protections, the erosion of traditional kinship networks, and trade agreements that advantage Australia and New Zealand. In contrast, mechanisms of assessing SDP are preoccupied with narrow measurable targets that focus on changing individual behaviours, like encouraging weight loss. Thus, indicator culture may enable the tracking of some useful evidence, but it does not disrupt the problematic rhetoric that purports foreign-funded interventions as solutions to domestic (Pacific) problems. If anything, it draws attention away 
from how higher-income countries have contributed to and exacerbated these problems, a point that is relevant in many areas of aid and development.

Distinct from more established domains of governance, SDP is a space in which there are active challenges and debates about how to effectively measure and evaluate interventions, uniquely positioning it as a site for the empirical study of indicator culture. The findings presented here offer a cautious endorsement of calls for SDP to follow international development's lead in studying governance, offering an alternative methodology for critically engaging the governance of development. ${ }^{64}$ Its implications are twofold. First, the identification of interactions between sometimes overlooked or unrecognised actants makes more aspects of governance transparent, which may facilitate strategic manoeuvres that foster greater engagement with underrepresented participants and grassroots knowledges. Secondly, the recognition that actor-networks - even those that appear solidified-rely on repetitions of specific performances suggests that emergent and established governance processes can change or dissolve. Recent developments in SDP, such as the closing of the UN Office of Sport for Development and Peace in 2017, evidence this volatility.

While there are expressed desires for developing and standardising evaluation methods for SDP, as well as contestation over what those practices should entail, the lack of agreed-upon indicators means a range of measurements and forms of expertise can intervene. The instability of SDP governance networks offer potential spaces for innovating and extending ANT's application to praxis-oriented goals. The recognition of the need for engagement between actants can be used to bring in actors who are not repeat players in governance networks. To give one example related to this study: there are research centres committed to developing health approaches and methods for Pacific populations from a Pacific perspective. One such tool is a validated quantitative instrument to more holistically assess the wellbeing of Pacific peoples. ${ }^{65}$ Incorporating it would require little adaptation for development contexts and balance desires for metrics and culturally appropriate measures. Further, doing so creates possibilities for its repeated interaction in and across governance networks, which can foster a wider valuing of these knowledges. Though using ANT in this way is largely untested, the one constant of ANT is that it encourages experimenting with and adapting its methods to make sense of intertwined semiotic-material relations. This commitment provides possibilities for thinking through how to engage — and not simply study_networks. 


\section{Bibliography}

Agathangelou, Anna M., and L.H.M. Ling. 'Desire Industries: Sex Trafficking, UN Peacekeeping, and the Neo-Liberal World Order.' The Brown Journal of World Affairs vol. 10, no. 1 (2003): 133-148.

Asdal, Kristin, Brita Brenna, and Ingunn Moser. Technoscience: The Politics of Interventions. Oslo: Oslo Academic Press, 2007.

Bevir, Mark, and R.A.W. Rhodes. Interpreting British Governance. London: Routledge, 2003.

Callon, Michel, and Bruno Latour. 'Unscrewing the Big Leviathan: How Actors Macro-Structure Reality and How Sociologists Help Them to Do So.' In Advances in Social Theory and Methodology: Toward an Integration of Micro- and Macro-Sociologies, edited by Karin D. Knorr-Cetina and Aaron V. Cicourel, pp. 277-303. New York: Routledge Press, 1981.

Casper, Monica, and Adele Clarke. 'Making the Pap Smear the 'Right Tool' for the Job: Cervical Cancer Screening in the USA, cerca 1940-1995.' Social Studies of Science vol. 28, no. 2 (1998): 255-290.

Crabtree, Benjamin F., and William L. Miller. Doing Qualitative Research. Thousand Oaks, CA: Sage, 1999.

Crawford, Kate, Jessa Lingel, and Tero Karppi. 'Our Metrics, Ourselves: A Hundred Years of Self-Tracking from the Weight Scale to the Wrist Wearable Device.' European Journal of Cultural Studies vol. 18, no. 4-5 (2015): 479-496.

Darnell, Simon C. 'Power, Politics, and Sport for Development and Peace: Investigating the Utility of Sport for International Development.' Sociology of Sport Journal vol. 27, no. 1 (2010): 54-75.

Darnell, Simon C., and Lyndsay Hayhurst. 'Hegemony, Postcolonialism, and Sport-forDevelopment: A Response to Lindsey and Gratton.' International Journal of Sport Policy and Politics vol. 4, no. 1 (2012): 111-124.

Davis, Kevin E. 'Legal Indicators: The Power of Quantitative Measures of Law.' Annual Review of Law and Social Science vol. 10 (2014): 37-52.

Davis, Kevin E., Benedict Kingsbury, and Sally E. Merry. 'Indicators as a Technology of Global Governance.' Law \& Society Review vol. 46, no. 1 (2012): 71-104.

Drahos, Peter, and Martin Krygier. 'Regulation, Institutions, and Networks,' Regulatory Theory: Foundations and Applications, edited by Peter Drahos, pp. 1-24. Canberra: ANU Press, 2017.

Friel, Sharon, Tung-liang Chiang, Youngtae Cho, Yan Guo, Hideki Hashimoto, Saroj Jayasinghe, Belinda Loring, Don Matheson, Huong Thanh Nguyen, and Mala Rao. 'Freedom to Lead a Life We Have Reason to Value? A Spotlight on Health Inequity in the Asia Pacific Region.' Asia Pacific Journal of Public Health vol. 23, no. 2 (2011): 246-263.

Gershon, Ilana. 'Bruno Latour.' In Agamben to Zizek: Contemporary Critical Theorists, edited by Jon Simons, pp. 161-176. Edinburgh: Edinburgh University Press, 2010.

Haraway, Donna. 'Situated Knowledges: The Science Question in Feminism and the Privilege of Partial Perspective.' Feminist Studies vol. 14, no. 3 (1988): 575-599.

Hayhurst, Lyndsay M.C. 'Corporatising Sport, Gender, and Development: Postcolonial IR Feminisms, Transnational Private Governance, and Global Corporate Social Engagement.' Third World Quarterly vol. 32, no. 3 (2011): 531-549. 
Hayhurst, Lyndsay M.C., and Wendy Frisby. 'Inevitable Tensions: Swiss and Canadian Sportfor-Development NGO Perspectives on Partnerships with High Performance Sport.' European Sport Management Quarterly vol. 10, no. 1 (2011): 75-96.

Henne, Kathryn. From the Academy to the UN and Back Again: The Traveling Politics of Intersectionality. Intersections: Gender and Sexuality in Asia and the Pacific 33 (2013), http://intersections.anu.edu.au/issue33/henne.htm

-- . Multi-Sited Fieldwork in Regulatory Studies. In Regulatory Theory: Foundations and Applications, edited by Peter Drahos, pp. 97-114. Canberra: ANU Press, 2017.

Jolly, Margaret, Helen Lee, Katherine Lepani, Anna Naupa, and Michelle Rooney. Falling through the Net? Gender and Social Protection in the Pacific. UN Women. Progress of the World's Women, 2015-2016.

Kidd, Bruce. 'A New Social Movement: Sport for Development and Peace.' Sport in Society vol. 11, no. 4 (2008): 370-380.

Larsen, Lotta Björklund. Shaping Taxpayers: Values in Action at the Swedish Tax Agency. New York: Berghahn, 2017.

Latour, Bruno. The Making of Law: An Ethnography of the Conseil d'Etat. Cambridge: Polity, 2009.

-- . Reassembling the Social: An Introduction to Actor-Network-Theory. Oxford: Oxford University Press, 2005.

Law, John. Organising Modernity. Oxford: Blackwell, 1994.

Lindsey, Iain. 'Governance in Sport-for-Development: Problems and Possibilities of (Not) Learning from International Development.' International Review for the Sociology of Sport (2016), Online First. DOI: 10.1177/1012690215623460

Lindsey, Iain, and Alan Gratton. 'An "International Movement"? Decentring Sport-forDevelopment within Zambian Communities.' International Journal of Sport Policy and Politics vol. 4, no. 1 (2012): 91-110.

Manuela, Sam, and Chris G. Sibley. 'The Pacific Identity and Wellbeing Scale (PIWBS): A Culturally-Appropriate Self-Report Measure for Pacific Peoples in New Zealand.' Social Indicators Research vol. 112, no. 1 (2012): 83-103.

Marcus, George E. 'Ethnography in/of the World System: The Emergence of Multi-Sited Ethnography.' Annual Review of Anthropology vol. 24 (1995): 95-117.

Merry, Sally E. 'Measuring the World: Indicators, Human Rights, and Global Governance.' Current Anthropology vol. 52, no. S3 (2011): S83-S95.

-- . The Seduction of Quantification: Measuring Human Rights, Gender Violence, and Sex Trafficking. Chicago: University of Chicago Press, 2016.

Merry, Sally E., Kevin E. Davis, and Benedict Kingsbury, eds. The Quiet Power of Indicators: Measuring Governance, Corruption, and Rule of Law. New York: Cambridge University Press, 2014.

Merry, Sally, and Summer Wood. 'The Paradox of Measurement: Child Rights in Tanzania.' Current Anthropology vol. 56, no. 2 (2015): 205-229.

Mosse, David. Cultivating Development: An Ethnography of Aid Policy and Practice. London: Pluto Press, 2004.

Nicholls, Sara, Audrey R. Giles, and Christabelle Sethna. "Perpetuating the "Lack of Evidence" Discourse in Sport for Development: Privileged Voices, Unheard Stories and Subjugated Knowledge.' International Review for the Sociology of Sport vol. 46, no. 3 (2010): 249264. 
Pottage, Alain. 'The Materiality of What?' Journal of Law and Society vol. 39, no. 1 (2012): $167-183$.

Schinkel, Willem. 'Sociological Discourse of the Relational: The Cases of Bourdieu and Latour.' Sociological Review vol. 55, no. 4 (2007): 707-729.

Sherry, Emma, Nico Schulenkorf, Matthew Nicholson, and Russell Hoyle. Tonga Netball Association Pacific Netball Partnerships Phase One Evaluation. Centre for Sport and Social Impact, LaTrobe University, 2014.

Webb, Andrew, and André Richelieu. 'Sport for Development and Peace in Action: Building Facts for Funding.' Journal of Sport and Social Issues vol. 40, no. 5 (2016): 432-456.

\section{Notes}

${ }^{1}$ Bevir and Rhodes, Interpreting British Governance, 1.

2 Drahos and Krygier, 'Regulation, Institutions, and Networks,' 12-16.

${ }^{3}$ See, for example, Darnell, 'Power, Politics, and Sport for Development and Peace'; Hayhurst, 'Corporatising Sport, Gender and Development.'

${ }^{4}$ Kidd, 'A New Social Movement.'

${ }^{5}$ Lindsey and Gratton, 'An "International Movement”?'

${ }^{6}$ Lindsey, 'Governance in Sport-for-Development.'

${ }^{7}$ Merry, The Seduction of Quantification, 9-10.

${ }^{8}$ I avoid language such as 'donor' or 'recipient' countries or other such misrepresentative framings. Any failures to do so are my own.

${ }^{9}$ Nicholls et al., 'Perpetuating the "Lack of Evidence" Discourse in Sport for Development.'

${ }^{10}$ Ibid., 250.

${ }^{11}$ Davis et al., 'Indicators as a Technology of Global Governance'; Merry et al., The Quiet Power of Indicators.

12 Asdal et al., Technoscience, 9.

${ }^{13}$ Latour, The Making of Law. Pottage ('The Materiality of What?') offers a comprehensive critique of this work.

${ }^{14}$ Even early on ANT never focused exclusively on science or technology (Callon and Latour, 'Unscrewing the Big Leviathan').

${ }^{15}$ Latour, Reassembling the Social.

${ }^{16}$ Gershon, 'Bruno Latour,' 163-167.

${ }^{17}$ An exception is Mosse, Cultivating Development.

${ }^{18}$ For a comparison between Bourdieu and Latour, see Schinkel, 'Sociological Discourse of the Relational.'

${ }^{19}$ Law, Organizing Modernity, 101.

${ }^{20}$ Wacjman, TechnoFeminism, 432; see also, for example, Casper and Clarke ('Making the Pap Smear the "Right Tool" for the Job').

${ }^{21}$ For a defence of ANT's approach to power, see Latour (Reassembling the Social). Larsen (Shaping Taxpayers) offers an example of an adaptation of ANT used to study governance.

${ }^{22}$ Haraway, "Situated Knowledges," 575-599.

${ }^{23}$ Merry, The Seduction of Quantification, 3.

${ }^{24}$ Davis, Kingsbury, and Merry, 'Indicators as a Technology of Global Governance,' 73-74.

${ }^{25}$ Merry, 'Measuring the World.'

${ }^{26}$ Davis, 'Legal Indicators,' 45.
} 
${ }^{27}$ Henne, 'From the Academy to the UN and Back Again.'

${ }^{28}$ Davis, 38.

${ }^{29}$ Merry, The Seduction of Quantification.

${ }^{30}$ Davis, 46.

31 Ibid., 46.

32 The Convention on the Rights of the Child is part of the multilateral treaty regime that creates the human rights system (United Nations, Convention on the Rights of the Child, accessed

November 12, 2015, http://www.ohchr.org/en/professionalinterest/pages/crc.aspx)

${ }^{33}$ Many thanks to Summer Wood for bringing this document to my attention.

${ }^{34}$ Merry and Wood, 'The Paradox of Measurement,' 214.

${ }^{35}$ Henne, 'Multi-sited Fieldwork in Regulatory Studies'; Merry, The Seduction of Quantification.

${ }^{36}$ Marcus, 'Ethnography in/of the World System.'

${ }^{37}$ Merry, The Seduction of Quantification.

${ }^{38}$ Gershon, 170-171.

${ }^{39}$ Latour, Reassembling the Social, 200-202.

${ }^{40}$ Gershon, 172-173. These scholars include Donna Haraway, Susan Leigh Starr, and Marilyn Strathern.

${ }^{41}$ Haraway, 'Situated Knowledges.'

42 Ibid., 581.

${ }^{43}$ Institutional ethics approval HREA A-13-35.

${ }^{44}$ Most documents were available through Australian government websites and offices, including DFAT, Australian Aid (before it was restructured as part of DFAT), and the Australian Sport Commission Clearinghouse for Sport (https://www.clearinghouseforsport.gov.au/), as well as from websites of SDP-specific organisations and partners (e.g., Sport Matters, National Rugby League). Some participants also allowed me to review nonconfidential planning documents that focused on SDP initiatives.

${ }^{45}$ All interviewees granted consent, and, when possible, I audio-recorded interviews. For interviews and observations, I took handwritten field notes (transcribed within a day of completion). In keeping with desires for anonymity, I limit my discussion of specific programs to those about which there is publically accessible information.

${ }^{46}$ Crabtree and Miller, Doing Qualitative Research.

${ }^{47}$ Lowy Institute for International Policy, Australian Foreign Aid, 2015, accessed April 1, 2016, http://www.lowyinstitute.org/issues/australian-foreign-aid.

${ }^{48}$ Australian Government. Australian Sports Diplomacy Strategy, 2015-18, accessed March 1, 2016. http://dfat.gov.au/about-us/publications/Documents/aus-sports-diplomacy-strategy-201518.pdf.

49 This concern emerged across four interviews conducted on September 6, 2012 and June 5, 2013.

${ }^{50}$ International Olympic Committee, 'Cooperation with the UN,' accessed April 29, 2015, http://www.olympic.org/content/olympism-inaction/idsdp/cooperation-with-the-un/

${ }^{51}$ Hayhurst and Frisby, 'Inevitable Tensions.'

${ }^{52}$ Most interviews took place prior to the introduction of the Sustainable Development Goals, which are detailed at http://www.un.org/sustainabledevelopment/sustainable-development-goals/

${ }^{53}$ Webb and Richelieu, 'Sport for Development and Peace in Action.'

${ }^{54}$ Friel et al., 'Freedom to Lead a Life We Have Reason to Value,' 248. 
55 Jolly et al., Falling through the Net?

${ }^{56}$ Friel et al.; Tonga's Ministry of Health attempted to establish quota restrictions on the consumption of low-quality meat, acknowledging associated health risks, but it was found to violate World Trade Organisation rules.

${ }^{57}$ Jolly et al.

${ }^{58}$ Ibid.

${ }^{59}$ Australian Government, Tonga Netball Strategy: Health Communication Strategy and Phase 1 Campaign Workplace, 2011-14. Australian Sports Outreach Program, 2011.

${ }^{60}$ Sherry et al., Tonga Netball Association Pacific Netball Partnerships Phase One Evaluation.

${ }^{61}$ Crawford et al., 'Our Metrics, Ourselves.'

62 Ibid.

${ }^{63}$ Agathangelou and Ling, 'Desire Industries,' 133.

${ }^{64}$ Lindsey, 1.

${ }^{65}$ Manuela and Sibley, 'The Pacific Identity and Wellbeing Scale (PIWBS).' 